\title{
A importância econômica do princípio da demanda efetiva em Keynes-Kalecki no âmbito da economia política
}

\author{
André Cutrim Carvalho" \\ David Ferreira Carvalho***
}

\begin{abstract}
Resumo
O objetivo do presente artigo é resgatar a relação de proximidade conceitual entre o princípio da demanda efetiva (PDE) de John Maynard Keynes e o PDE de Michael Kalecki. De acordo com o PDE, os agentes econômicos determinam o nível do produto e, por conseguinte, do emprego quando tomam a decisão de produzir ou de investir em uma economia monetária da produção capitalista. Keynes e, mais adiante, Kalecki criaram um legado por meio de uma nova taxonomia, que conferiu à economia política uma estrutura conceitual diferente, para criticar a Lei de Say e, também, os fundamentos pertencentes à ortodoxia econômica (neo)clássica.
\end{abstract}

Palavras-chave: Princípio da demanda efetiva. Keynes. Kalecki. Lei de Say. Economia política.

* Doutor em Desenvolvimento Econômico, com pós-doutorado em Economia no Instituto de Economia da Universidade Estadual de Campinas (Unicamp). Professor pesquisador da Faculdade de Ciências Econômicas (Facecon) e do Programa de Pós-Graduação em Gestão de Recursos Naturais e Desenvolvimento Local na Amazônia (PPGEDAM) da Universidade Federal do Pará (UFPA). E-mail: andrecc83@gmail.com

** Doutor em Economia, com pós-doutorado em Economia no Instituto de Economia da Unicamp. Professor pesquisador da Facecon da UFPA. E-mail: david.fcarvalho@yahoo.com.br

http://dx.doi.org/10.5335/rtee.v25i52.12260

Submissão: 11/09/2019. Aceite: 14/05/2020. 


\section{Introdução}

Numa perspectiva teórica, o princípio da demanda efetiva (PDE), nas versões de John Maynard Keynes e Michal Kalecki, diferentemente da Lei de Say, de suporte às teorias econômicas dos clássicos e neoclássicos - que pressupõem erradamente que todo o dinheiro ganho pelos agentes econômicos é gasto na compra de fatores de produção e de que toda a renda gerada da produção de bens e serviços é, por sua vez, toda ela gasta na compra desses bens e serviços -, apresenta uma determinação causal multilateral para a identidade contábil entre despesas, produção e renda, ao contrário da formulação da determinação simultânea dessas variáveis dos modelos neoclássicos.

O PDE define claramente que em uma economia capitalista são os gastos autônomos (de consumo e investimento) que determinam a renda agregada de tal economia, isto é, o sentido da determinação é do gasto para a renda, e não o contrário, como supõe a Lei de Say. Como se observa, Kalecki confirma, com outras palavras, as observações críticas já realizadas por Karl Marx e John Maynard Keynes contra a inconsistência da Lei de Say.

A decisão de consumir (gastos das famílias) e a decisão de investir (gastos dos empresários) situam-se no âmbito microeconômico. Assim, se admitirmos o primado das decisões de consumir, a poupança não passará de um resíduo. É importante reconhecer, com base no princípio da demanda efetiva, que a decisão de consumir e a de investir determinam a renda agregada de uma economia nacional.

Deste modo, supondo que as decisões de investir ex ante se tornem efetivas, no sentido de virem se realizar ex post, é inevitável reconhecer que as decisões de investir poderão restringir os gastos de consumo ou ampliar a renda. Nessas condições, todo ato de investimento acaba, por si mesmo, determinando que a poupança aumente numa quantidade equivalente.

Isso ocorre porque há reações psicológicas habituais, entre os agentes no mercado, que permitem alcançar um nível de preços de equilíbrio no qual a disposição de comprar é igual à disposição de vender. Como o ato mercantil-monetário de compra e venda no mercado, para se realizar, depende do comprador - porque possuidor do dinheiro como equivalente geral -, então a existência de um valor de mercado para produção é, ao mesmo tempo, uma condição necessária para que a renda nominal tenha um valor monetário e uma condição suficiente para expressar o montante do valor monetário agregado da poupança e do investimento daqueles que decidem investir.

Teoria e Evidência Econômica - a. 25, n. 52, p. 182-202, jan./jun. 2019 
Os montantes da renda agregada e da poupança agregada são resultados das tomadas de decisões da livre opção dos indivíduos sobre se irão consumir ou não, sobre se irão investir ou não. É evidente, como visto em Keynes (1996) e Torr (1997), que os montantes agregados não são independentes das decisões de consumir e de investir.

Na Teoria Geral de Keynes (1996), o significado de consumo não está associado ao conceito de utilidade, ou seja, a ideia de que um bem ou serviço deve proporcionar satisfação máxima ao consumidor. $\mathrm{Na}$ verdade, o consumo é tomado como gasto, isto é, um importante componente do total dos gastos da demanda agregada. Numa economia monetária da produção, o consumo é gasto porque é ancorado no princípio da demanda efetiva, que afirma que são os gastos que determinam a renda, e não o contrário, como supõe o princípio de Say.

O objetivo do presente artigo é apresentar a relação de proximidade conceitual entre o PDE de Keynes e o PDE de Kalecki. De acordo com o PDE, os agentes econômicos determinam o nível do produto e, por conseguinte, do emprego quando tomam a decisão de produzir ou de investir. A elevada capacidade lógica desses dois autores permitiu a construção de uma nova taxonomia, que confere à economia política uma estrutura conceitual diferente, para criticar a Lei de Say e os fundamentos da economia (neo)clássica.

Isso posto, o presente artigo foi dividido em quatro seções, além desta seção introdutória e das considerações finais. Na segunda seção, o PDE em Keynes é apresentado em paralelo ao PDE em Kalecki; na terceira, este artigo propõe entender o esquema de reprodução do capital em Kalecki como instrumento da demanda efetiva, além de recuperar a polêmica que ficou conhecida como "equívoco de Bacha e a crítica de Almeida" nos termos do PDE kaleckiano.

\section{O princípio da demanda efetiva em Keynes-Kalecki: uma (inter)ligação conceitual necessária}

No capítulo 3 da sua obra The general theory of employment, interest and money, também conhecida por A teoria geral do emprego, do juro e da moeda ou, simplesmente, Teoria Geral, publicada no ano de 1936, John Maynard Keynes criou uma taxonomia específica não só para desenvolver o seu princípio da demanda efetiva (PDE), mas também para demonstrar que a Lei de Say seria um caso especial e não aplicável aos fatos da experiência numa economia monetária da produção

Teoria e Evidência Econômica - a. 25, n. 52, p. 182-202, jan./jun. 2019 
capitalista. Isso porque a Lei de Say pressupõe que o gasto corrente é igual ao produto corrente produzido por trabalhadores empregados no período corrente. As categorias $D_{1}$ e $D_{2}$ utilizadas por Keynes, apesar de lembrarem as formas de expressão dos departamentos produtores de bens de consumo $\left(D_{1}\right)$ e de bens de capital $\left(D_{2}\right)$ do famoso esquema de reprodução ampliado do capital de Karl Marx, distinguem-se por estarem associadas diretamente à determinação do volume do emprego efetivo, ex ante, pelo PDE.

Contudo, as categorias $D_{1}$ e $D_{2}$ foram desenvolvidas por Keynes (1996) especificamente para demonstrar que a Lei de Say dos clássicos é um caso específico e não aplicável aos fatos da experiência de uma economia capitalista. A Lei de Say supõe que o gasto corrente é igual ao produto corrente produzido pelos trabalhadores empregados hoje, logo, as categorias $D_{1}$ e $D_{2}$ de Keynes também tiveram de ser definidas em termos de gasto corrente e produto corrente, para que a análise geral do sistema de Keynes pudesse ser comparável com o caso especial do sistema clássico.

É essa taxonomia de Keynes que distingue sua análise econômica geral da análise especial dos clássicos e neoclássicos. Robinson (1979, p. 08), discutindo como se pode diferenciar a ideologia de ciência, observa que, para dirimir certas divergências, não adianta se apelar para uma definição puramente lógica, pois, para ela, precisamos não de definições, e sim de critérios, exemplificando com o exemplo do cisne:

Se a palavra "cisne" é utilizada para descrever um pássaro que tem, entre outras características, a de parecer branco, então os pássaros negros da Austrália têm que ser chamados por outro nome; mas se os critérios para ser cisne não são anatômicos, sem menção de cor, então os cisnes negros e brancos estão na mesma categoria.

O sucesso de um bom esquema de classificação nas ciências físicas e biológicas - baseado em algum critério - requer que o taxonomista defina cada categoria com precisão, em termos daquelas propriedades comuns, necessárias e suficientes, possuídas pelo objeto estudado, e/ou por alguma função comum que possa servir para enquadrar o objeto estudado como membro de uma classe específica, como ressalta Paul Davidson (1994).

Davidson (1994), talvez inspirado em Joan Robinson (1979), faz uso de dois exemplos interessantes das ciências exatas, em comparação com a ciência econômica, para demonstrar o problema semântico do emprego de palavras idênticas com sentidos diferentes nas ciências econômicas. Por exemplo: a baleia é um animal marinho que parece com o peixe, nada como o peixe e morrerá como um peixe se ficar fora d'água por muito tempo, porém, ainda assim, a baleia não é classificada 
pela ciência biológica como peixe, e sim como mamífero, pois o que a baleia possui de comum com todos os mamíferos da terra é um órgão especializado que serve para amamentar os seus filhotes. Assim, a aparência física da baleia, seu habitat e sua capacidade de nadar são apenas condições necessárias, mas não são suficientes para que os biólogos a classifiquem como peixe.

Na ciência física, os taxonomistas com frequência inventam palavras para definir certas categorias específicas. Por exemplo: certas coisas que possuem propriedades comuns são chamadas de quarks ${ }^{1}$. Mesmo assim, a maioria das pessoas não têm a menor ideia do que é um quark. Por isso mesmo, a palavra quark não aparece, com frequência, nas conversas entre as pessoas comuns no cotidiano. Físicos, por conseguinte, são livres para definir um quark de uma maneira que eles veem de forma correta para a comunidade científica. Porém, os economistas, ao contrário dos físicos, divergem quanto ao uso comum dos termos usados por eles.

$\mathrm{Na}$ ciência econômica, ao contrário das ciências exatas, a existência de diferentes "escolas de pensamento econômico" impede qualquer possibilidade de conciliação teórica sobre determinadas questões. Por isso, os economistas - diferente dos físicos - encontram sérias dificuldades de comunicação social quando criam palavras, restritas ao uso da sua comunidade científica, porque a ciência econômica, como uma ciência social, embora tenha um objeto comum de análise - a economia capitalista -, ainda não é suficientemente unificada teoricamente para evitar as diferentes interpretações sobre o mesmo fenômeno econômico.

Disso resulta que, devido ao emprego de termos idênticos com significados completamente diferentes entre as distintas escolas de pensamento econômico, o leigo fique confuso quando os economistas usam as mesmas palavras e dão interpretações diferentes sobre os mesmos fenômenos, por exemplo, o da inflação e o do desemprego. Além disso, às vezes, as interpretações científicas dos fatos entram em choque com o senso comum arraigado secularmente.

Infelizmente, os economistas não têm a mesma liberdade linguística dos físicos. Para os economistas se comunicarem com os policy makers e outros públicos que lidam com problemas econômicos, eles costumam usar palavras utilizadas fora do padrão do senso comum em suas falas no cotidiano, para designar suas categorias econômicas com rigor. $\mathrm{O}$ efeito disso é que, com frequência, os defensores de alguma posição econômica estão usando termos econômicos para explicar alguma coisa, enquanto os seus opositores estão usando os mesmos termos para a conotação de coisas diferentes. 
Essa ambiguidade da linguagem e da comunicação dos economistas, frequentemente, perpetua mais confusões semânticas do que esclarecimentos sobre os problemas econômicos. Por isso, Keynes (1996) fazia questão de formular os seus termos esclarecendo as diferenças e semelhanças com o uso já empregado há algum tempo pelas pessoas do mundo dos negócios e pelo senso comum.

\section{O princípio da demanda efetiva em Michal Kalecki: conceito e caracterização}

A formulação do PDE por Kalecki é simples e logicamente clara, identificada no essencial à formulada por Possas, exceto por fazê-lo em termos agregados e no âmbito de uma teoria da dinâmica capitalista - com os cortes analíticos simplificadores de uma economia fechada, embora possa também ser formulada para uma economia aberta -, e não como um "princípio" mais geral e simples, como o formulado por Possas (1987).

A formulação lógica do PDE de Kalecki (1983) encontra-se na seção 3 do seu livro A teoria da dinâmica econômica, quando trata dos determinantes dos lucros numa economia fechada e expressa a relação entre renda e gastos da seguinte maneira:

Lucros brutos + Salários e ordenados = Investimento bruto +

Consumo dos capitalistas + consumo dos trabalhadores

Supondo que os trabalhadores não poupam, então o consumo dos trabalhadores será igual à sua renda ganha, ou seja, os salários e ordenados, tal que:

$$
\text { Salários e ordenados = Consumo dos trabalhadores }
$$

Assim, conclui-se que essa equação pode ser simplificada para a forma:

Lucros brutos $=$ Investimento bruto + consumo dos capitalistas

O que significa essa equação? O próprio Kalecki (1983, p. 36) responde:

Quer dizer que os lucros em um dado período determinam o consumo e o investimento dos capitalistas? Ou o contrário? A resposta depende de qual item estar diretamente sujeito às decisões dos capitalistas. Ora, é claro que os capitalistas podem decidir consumir e investir mais num dado período que no precedente, mas não podem decidir ganhar mais. Portanto, são suas decisões (de gastos) quanto a investimento e consumo que determinam os lucros e não vice-versa.

Teoria e Evidência Econômica - a. 25, n. 52, p. 182-202, jan./jun. 2019 
Recorrendo à lógica pura, Kalecki (1983) conseguiu formular de forma diferente o "princípio da demanda efetiva". Nota-se que os capitalistas podem decidir quanto investirão e quanto consumirão no futuro, mas não podem decidir de quanto serão suas vendas e seus lucros no tempo futuro. Esta última decisão não pertence ao vendedor da mercadoria, mas ao seu comprador.

Adaptando as equações de reprodução de Karl Marx para uma economia moderna, Kalecki (1977) tomou como hipótese simplificadora que os trabalhadores não poupam. Nas palavras de Carvalho e Carvalho (2018, p. 237):

Além disso, negligenciou a possibilidade de acumulação de estoques de produtos acabados e não vendidos, considerando-o um fenômeno passageiro. Com isso, foi possível chegar à "equação de trocas" fundamental de Marx entre os departamentos produtores de bens de investimento (I) e bens de consumo dos capitalistas (II), de um lado, e o departamento produtor de bens de consumo dos trabalhadores (III), de outro.

Nesse esquema de reprodução, dada a distribuição da renda entre lucros e salários nos três departamentos, os gastos com bens de investimento (I), com bens de consumo dos capitalistas $(\mathrm{Cc})$ e com bens de consumo dos trabalhadores $(\mathrm{Cw})$ determinam a renda agregada $(\mathrm{Y})$, podendo ser expressa nos seguintes termos, apresentados em Carvalho e Carvalho (2018):

$$
\mathrm{Y}=\mathrm{I}+\mathrm{Cc}+\mathrm{Cw}
$$

Fazendo em $\mathrm{P}$, W e $P_{3}$, temos:

$$
\begin{gathered}
\mathrm{P}=P_{1}+P_{2}+P_{3} \\
\mathrm{~W}=W_{1}+W_{2}+W_{3} \\
P_{3}=W_{1}+W_{2}
\end{gathered}
$$

Em que:

$P_{1}, P_{2}$ e $P_{3}$ são os lucros brutos; $W_{1}, W_{2}$ e $W_{3}$ são os montantes de salários dos três departamentos; e P e W são, respectivamente, o total dos lucros e o total dos salários. Assim, pode-se escrever:

$$
\mathrm{P}+\mathrm{W}=\mathrm{Y}=\mathrm{I}+C_{k}+C_{w}
$$

$\mathrm{Ou}$

$$
\mathrm{P}+\mathrm{W}-C_{w}=\mathrm{I}+C_{k}
$$


Supondo que os trabalhadores não poupam, então, $C_{k}=$ W. Nessa situação, como determinam Carvalho e Carvalho (2018), a equação (6) é reduzida para a seguinte expressão:

$$
\mathrm{P}=\mathrm{I}+C_{k}
$$

Pela equação (7), fica claro que, em uma economia fechada e sem governo, os lucros dos capitalistas são determinados pelos seus próprios gastos em bens de investimento e de consumo. De outro modo, dado que os trabalhadores não poupam, os salários e a produção do departamento de bens de consumo assalariado são determinados pelos gastos dos capitalistas e pela distribuição de renda nos três departamentos.

Seja a participação dos salários na renda de cada departamento dada por $W_{1}, W_{2}$ e $W_{3}$, tal que:

$$
w_{1}=\frac{W_{I}}{I} ; w_{2}=\frac{W_{I I}}{C_{k}} ; w_{3}=\frac{W_{3}}{C_{w}}
$$

Ou ainda:

$$
W_{1}=w_{1} \mathrm{I} ; W_{2}=w_{2} C_{k} ; W_{3}=w_{3} C_{w}
$$

Substituindo na equação (4) os parâmetros de (9), obtém-se:

$$
P_{3}=w_{1} I+w_{2} C_{k}
$$

Como $C_{w}=P_{3}+W_{3}$, tem-se:

$$
P_{3}=C_{w}-W_{3}
$$

Substituindo (11) em (10), obtém-se:

$$
C_{w}-W_{3}=w_{1} I+w_{2} C_{k}
$$

Assim:

$$
W_{3}=w_{3} C_{w}
$$


Substituindo (13) em (12), tem-se:

$$
\begin{gathered}
C_{w}-w_{3} C_{w}=w_{1} I+w_{2} C_{k} \\
\left(1-w_{3}\right) C_{w}=w_{1} I+w_{2} C_{k}, \text { donde: } \\
C_{w}=\frac{w_{1} I+w_{2} C_{k}}{1-w_{3}}
\end{gathered}
$$

Quando ocorrem variações nos gastos dos capitalistas, a produção do D3 se desloca até o ponto em que os lucros brutos desse departamento sejam iguais aos salários dos departamentos D1 e D2. Substituindo (14) em (1), obtém-se:

$$
\mathrm{Y}=\mathrm{I}+C_{k}+C_{w}=\mathrm{I}+C_{k}+\frac{w_{1} I+w_{2} C_{k}}{1-w_{3}}
$$

A equação (15) expressa que o total dos lucros dos capitalistas depende dos seus próprios gastos em bens de investimentos e bens de consumo, e não o inverso, uma vez que essas decisões precisam de um determinado período de tempo para que possam efetivar-se, independentemente do nível dos lucros correntes. Com efeito, sempre que os capitalistas, enquanto classe, realizarem um gasto, no mesmo período, a este corresponderá um montante de lucros de igual valor.

Em Luta de classes e distribuição da renda nacional, Kalecki (1977, p. 92) procura demonstrar a inconsistência lógica da teoria do "esmagamento do lucro" pelo aumento do salário, num modelo simplificado de uma economia fechada e sem governo, formula a hipótese restritiva - posteriormente liberada, quando então amplia o seu modelo simplificado para um modelo genérico de uma economia com governo e aberta ao mercado externo - de que iria "considerar realisticamente que os trabalhadores gastam toda a sua renda e a gastam imediatamente".

Deriva daí a já famosa frase de Robinson (1979, p. 87), de que Kalecki reuniu uma teoria de curto prazo da distribuição da renda, ligada ao grau de monopólio, com uma teoria de longo prazo baseada no PDE, de que "os trabalhadores gastam o que ganham e os capitalistas ganham o que eles gastam". É evidente, porém, que o suposto de que os trabalhadores gastam o que ganham, isto é, de que os trabalhadores não poupam parte de sua renda-salário, é apenas uma simplificação até certo ponto realista. 
Mas a hipótese restritiva de um modelo de uma economia capitalista fechada e sem governo de Kalecki, na qual "os trabalhadores gastam o que ganham e os capitalistas ganham o que gastam", poderia - ainda que compreensível para fins de sua exposição didática - dar uma falsa impressão de que o princípio da demanda efetiva em Kalecki, quanto ao sentido da determinação, somente seria aplicado aos capitalistas que "ganham o que gastam", e não aos trabalhadores que "gastam o que ganham".

No entanto, independentemente do montante dos lucros ou prejuízos do capitalista em função de sua decisão de gastar ou não; ou do trabalhador de poupar ou não, o sentido lógico da determinação que deve sustentar o princípio da demanda efetiva geral é o de que são as decisões dos gastos dos capitalistas - comprando tanto bens de investimentos quanto bens de consumo - e as decisões de gastos dos trabalhadores (comprando bens e serviços de consumo) que determinam a renda agregada numa economia fechada e sem governo.

Neste ponto, cabe seguir duas observações importantes de Possas (1987). A primeira, de que a contribuição teórica de Kalecki, sobre a questão da distribuição da renda funcional, não é a única forma de abordagem do tema no contexto da demanda efetiva, mesmo porque há que se distinguir entre o "princípio" da demanda efetiva e uma "teoria" da demanda efetiva, que contenha determinados supostos sujeitos à demonstração sobre a dinâmica de funcionamento do capitalismo relativa à questão específica do emprego efetivo que recorra ao PDE ou pelo menos seja com ele compatível. Neste particular, é justamente como teoria da demanda efetiva, em seus próprios termos, que a explicação de Michal Kalecki se sustenta como original. A segunda, complementando a primeira observação, diz respeito à necessidade de ressaltar que a importância da teoria da distribuição da renda funcional em Kalecki se dá no contexto da sua teoria da dinâmica capitalista, mas não quanto à determinação da renda agregada e nem mesmo no âmbito das decisões de investimento dos empresários que constituem o fundamento estratégico da dinâmica capitalista.

Neste caso, como determinam Possas e Baltar (1981), a exposição da teoria da distribuição da renda de Kalecki é bem didática, no sentido de apresentar a distribuição funcional da renda como uma variável condicionante, mas não determinante da dinâmica capitalista baseada no princípio da demanda efetiva. Ademais, a teoria da distribuição de renda de Kalecki não trata esta variável no exato termo do tempo econômico de Keynes: o curto período tomado ex ante.

De fato, o tempo em Kalecki tem outro significado dado por uma determinada defasagem, no curto prazo, entre o período das tomadas de decisões de gastos pelos 
agentes econômicos e o período em que essas decisões tomadas são efetivadas, como se pode conferir pela seguinte frase do próprio Kalecki (1979, p. 92):

Podemos considerar realisticamente que os trabalhadores gastam toda a sua renda e a gastam imediatamente. Contrastando com isso, podemos supor que o volume de investimento e consumo dos capitalistas é determinado por decisões tomadas antes do curto período de tempo em consideração e não são afetados assim pela elevação de salários durante esse período.

O tempo em Kalecki, como ressalta Possas (1987), é meramente contábil em suas equações, por isso ex post, com que o tempo econômico em termos de "período" se reduz a intervalos de referências arbitrários ou a "prazos" de gestação ou maturação de investimentos - que são de natureza estrutural -, e não o tempo relativo às decisões de produção ou de investimentos por parte dos empresários.

Não obstante, apesar dessas diferenças quanto ao tratamento do tempo, Kalecki e Keynes se aproximam quando admitem que as tomadas de decisões dos capitalistas, no curto período, são baseadas na experiência corrente. De fato, como visto em Possas (1987), a intenção de Keynes na sua Teoria Geral, quando ressalta a importância da distribuição da renda como um dos fatores institucionais restritivos à função da demanda agregada ou do consumo das famílias, foi também mostrar a distribuição da renda como uma variável condicionante importante, mas não como uma variável determinante da renda agregada.

Não resta dúvida de que Marx (1980) tinha conhecimento da insuficiência da demanda efetiva sobre a dinâmica da economia capitalista, porém, ele não investigou o problema da demanda efetiva, pelo menos na forma como é hoje conhecida. Coube a Kalecki (1977) tomar o esquema de reprodução ampliada de Marx como ponto de partida para a formulação da sua teoria da demanda efetiva. Resolveu-se discutir o PDE de Kalecki por causa de equívocos que costumam, às vezes, surgir quando não é feita uma leitura atenta da lógica da exposição desse princípio na obra do autor.

\section{Esquema de reprodução do capital em Kalecki: em busca da demanda efetiva}

Embora tome o esquema de reprodução ampliada do capital de Marx, Kalecki (1977) modifica um pouco a representação da estrutura da economia capitalista em departamentos, com o propósito de simplificar a sua argumentação para se concentrar no problema básico de como se realiza a mais-valia social numa economia 
moderna fechada (sem o comércio exterior) e sem governo, quanto à abstração das receitas tributárias e despesas governamentais, como determina Feiwel (1981).

Para isso, em primeiro lugar, em vez de incluir no Departamento I somente a produção de bens de produção, Kalecki (1977) supõe que esse Departamento I supre o valor total do investimento bruto, compreendendo aí as matérias-primas respectivas. No departamento produtor de bens de consumo, também são incluídas as matérias-primas respectivas em todas as fases do processo produtivo.

Kalecki (1977), mantendo-se inteiramente de acordo com o método de Marx, distingue dois departamentos especializados na produção de bens de consumo: 0 Departamento II, produtor de bens de consumo, para os capitalistas; e o Departamento III, produtor de bens de consumo, para os trabalhadores. Tendo-se isso em conta, o esquema de Kalecki pode representar a renda nacional combinando uma agregação setorial com uma agregação global, tal qual a matriz de fluxos de renda ou valor agregado do Quadro 1.

Quadro 1 - Esquema de reprodução econômica de Kalecki

\begin{tabular}{|c|c|c|c|}
\hline \multicolumn{2}{|c|}{ Departamentos Industriais } & \multirow{2}{*}{ Total } \\
\hline I & II & III & P \\
\hline P1 & P2 & P3 & W \\
\hline W1 & W2 & W3 & Y \\
\hline
\end{tabular}

Fonte: Kalecki (1977).

Em que P1, P2 e P3 são os lucros brutos (antes de deduzir a depreciação) dos três departamentos; W1, W2 e W3 são, respectivamente, os montantes dos salários; P e W são os lucros brutos totais e os salários totais, respectivamente; Cc, o consumo dos capitalistas, $\mathrm{Cw}$, o consumo dos trabalhadores; e Y, a renda nacional bruta (antes de deduzir a depreciação).

Como faz Kalecki, seguindo a abordagem de Marx, ao supor que os trabalhadores não poupam, sem considerar o problema da possível acumulação de estoques de bens não vendidos, considerando tal possibilidade apenas como um fenômeno temporário, é fácil agora chegar à fundamental "equação de troca" entre o Departamento I e o Departamento II, de um lado, e o Departamento III, de outro.

Os salários pagos pelos capitalistas do Departamento III aos seus trabalhadores são gastos na aquisição de parte dos bens de consumo dos trabalhadores produzidos por esse departamento. Os lucros totais dos capitalistas do Departamento III 
são materializados na forma dos bens de consumo dos trabalhadores que restaram para os capitalistas depois de pagos os salários W3 - salários estes que são destinados à compra de igual valor de bens de consumo dos trabalhadores.

Isso posto, como pontuado por Kalecki (1977), os bens de consumo dos trabalhadores no valor P3 são vendidos aos trabalhadores dos Departamentos I e II, tal que:

$$
\mathrm{P} 3=\mathrm{W} 1+\mathrm{W} 2
$$

Assim, admitida a distribuição de renda entre lucros e salários nos três departamentos, o Investimento (I) e o Consumo dos capitalistas (Cc) determinam os lucros e a renda nacional. De fato, somando P1 + P2 a ambos os lados da equação (1), tem-se:

$$
\mathrm{P} 1+\mathrm{P} 2+\mathrm{P} 3=\mathrm{P} 1+\mathrm{P} 2+\mathrm{W} 1+\mathrm{W} 3
$$

Ou, reorganizando (2):

$$
\mathrm{P} 1+\mathrm{P} 2+\mathrm{P} 3=\mathrm{P} 1+\mathrm{W} 1+\mathrm{P} 2+\mathrm{W} 3
$$

Pelo esquema de Kalecki, podemos escrever as seguintes equações parciais:

$$
\begin{aligned}
& \mathrm{P}=\mathrm{P} 1+\mathrm{P} 2+\mathrm{P} 3 \\
& \mathrm{I}=\mathrm{P} 1+\mathrm{W} 1 \\
& \mathrm{Cc}=\mathrm{P} 2+\mathrm{W} 2 \\
& \mathrm{Cw}=\mathrm{P} 3+\mathrm{W} 3
\end{aligned}
$$

Substituindo as equações parciais na equação (3), tem-se:

$$
\mathrm{P}=\mathrm{I}+\mathrm{Cc}
$$

Fazendo:

$$
w_{1}=\frac{W_{1}}{I} \quad w_{2}=\frac{W_{2}}{C c} \quad w_{3}=\frac{W_{3}}{C w}
$$

Substituindo na equação (1) as relações representadas por $w_{1} ; w_{2} \mathrm{e} \mathrm{w}_{3}$, depois de um algebrismo, tem-se:

$$
P_{3}=w_{1} I+w_{2} C c
$$

Substituindo P3 = Cw - W3 na equação (5), tem-se:

$$
\mathrm{Cw}-w_{3} C w=w_{1} I+w_{2} C_{c}
$$


Ou, ainda:

$$
\left(1-w_{3}\right) C w=w_{1} I+w_{2} C c
$$

Assim, para o consumo dos trabalhadores, a equação final é dada por:

$$
C w=\frac{w_{1} I+w_{2} C c}{1-w_{3}}
$$

A renda nacional (Y) de um país é determinada pelos gastos destinados na compra de bens de investimento (I) e nas compras de bens de consumo dos capitalistas $(\mathrm{Cc})$ e nas compras de bens de consumo dos trabalhadores, tal que:

$$
\mathrm{Y}=\mathrm{I}+\mathrm{Cc}+\mathrm{Cw}
$$

Substituindo (8) em (9), tem-se:

$$
\mathrm{Y}=\mathrm{I}+\mathrm{Cc}+\mathrm{Cw}=\mathrm{I}+\mathrm{Cc}+\frac{w_{1} I+w_{2} C c}{1-w_{3}}
$$

Pela equação (10), a renda (ou produto) nacional Y que se pode vender e os lucros $(\mathrm{P})$ que se podem realizar são determinados, em qualquer circunstância, e não apenas no caso da reprodução ampliada, pelos gastos de investimentos (I) e de consumo dos capitalistas serem determinados pelos lucros e pela renda nacional, aponta Kalecki (1977). A razão disso é que o investimento e o consumo dos capitalistas, no curto prazo, resultam de decisões tomadas no passado e devem ser consideradas como dadas.

As vendas e os lucros num dado período não podem ser o resultado direto das decisões passadas. De fato, nas palavras de Kalecki (1977, p. 03): "Os capitalistas podem decidir quanto investirão e consumirão no próximo ano, mas não podem decidir a respeito de quanto serão suas vendas e seus lucros”. Essa frase traduz o significado lógico do núcleo da moderna teoria da demanda efetiva.

$\mathrm{O}$ que significa a equação $\mathrm{P}=\mathrm{I}+\mathrm{Cc}$ ? Significa que os lucros determinam os gastos de consumo e de investimentos dos capitalistas? Ou o contrário? A resposta a essas perguntas depende de qual das variáveis está sujeita às decisões dos capitalistas. De fato, a resposta a que chegou Kalecki (1977, p. 36) se baseia em pura lógica e é assim expressa: "Ora, é claro que os capitalistas podem decidir consumir e investir mais num dado período que no precedente, mas não podem decidir 
ganhar mais. Portanto, são suas decisões quanto ao investimento e consumo que determinam os lucros e não vice-versa".

Desse modo, por essa afirmação de Kalecki, fica evidente que os empresários não têm poder de decisão sobre os seus lucros no momento que tomam decisões, mas sobre os seus gastos, sobretudo os de investimento e de consumo. Essa é uma demonstração lógica do princípio da demanda efetiva de Kalecki. Fica claro, também, que são os gastos de investimento e de consumo, em uma economia fechada e sem governo, que determinam os níveis da renda nacional e dos lucros que poderão ser realizados, e não o contrário. Como recorda Possas (1987), na visão de Kalecki, num período curto, o investimento e o consumo dos capitalistas são determinados por decisões que tomaram forma no período anterior.

No caso daquelas decisões de gastos de investimentos em bens industriais (bens de capital fixo), leva algum tempo para que os empresários ponham em operação seu equipamento de capital fixo, e é somente com certa demora (defasagem) que o consumo dos capitalistas responde às mudanças nos fatores que o influenciam.

De verdade, a atividade de investimento compreende uma sequência de fases que se inicia com a tomada de decisão, seguida de encomenda, construção e entrega do equipamento de capital ao empresário-investidor, para posterior operação. Já as mudanças no consumo dos capitalistas também acompanham as modificações nos lucros com algum retardo, como consta em Kalecki (1977).

Há, ainda, o fato de as decisões dos empresários, quanto ao consumo e ao investimento em geral, serem tomadas em termos reais e entrementes, isto é, nesse intervalo de tempo, os preços dos bens de consumo e de investimento podem mudar. Neste caso, uma peça de equipamento de capital encomendada ao fabricante pode custar mais caro agora do que quando foi emitido o pedido. Por isso, para superar esse problema, Kalecki sugere que os dois membros das equações (4) e (10) sejam tomados a preços constantes.

As decisões dos capitalistas quanto ao seu investimento e ao seu consumo são tomadas não em termos nominais, mas "reais", isto é, I e Cc devem ser calculados a preços constantes. Se $w_{1} ; w_{2} \mathrm{e} \mathrm{w}_{3}$ são estáveis e as taxas nominais de salários em todos os três departamentos variam na mesma proporção, a mesma variação ocorrerá no caso dos preços da produção desses departamentos. Além disso, como se pode observar, as equações (4) e (8) são também válidas em termos "reais".

Nessas circunstâncias, um aumento "real" no consumo dos capitalistas ou no investimento resulta numa expansão do produto do Departamento II, Cw, a fim de

Teoria e Evidência Econômica - a. 25, n. 52, p. 182-202, jan./jun. 2019 
prover um excedente, P3, nesse departamento, o bastante para cobrir a demanda efetiva gerada pelo aumento dos salários totais dos Departamentos I e II. Contudo, é bom observar que tal possibilidade só se concretizará se houver capacidade ociosa nesse departamento.

Na hipótese da não ocorrência de capacidade ociosa, $\mathrm{Cw}$ então será constante em termos reais, que pode ser representada por B. Nesse caso, um aumento no valor nominal da soma dos salários dos Departamentos I e II, W1 + W2, causará uma elevação dos preços, e não da produção dos bens de consumo dos trabalhadores. Como consequência, o valor real do total dos salários nos três departamentos, W1, W2 e W3, será reduzido em comparação com o nível de produção que atingiria se houvesse capacidade ociosa no Departamento III.

Por conseguinte, as razões do tipo: $w_{1}=\frac{W_{1}}{I}, w_{2}=\frac{W_{2}}{C c}$ e $w_{3}=\frac{W_{3}}{C w}=\frac{W_{3}}{B}$, com todas as variáveis expressas em termos "reais", declinarão em proporção inversa ao aumento dos preços dos bens de consumo dos trabalhadores. Nessa situação, como $\mathrm{Cw}=\mathrm{B}$, a equação (8) pode ser reescrita na seguinte forma:

$$
B=\frac{w_{1} I+w_{2} C c}{1-w_{3}}
$$

Por fim, nota-se que Kalecki não contempla na sua teoria da demanda efetiva a incerteza e, com ela, a teoria da expectativa no sentido atribuído por John Maynard Keynes. Contudo, do ponto de vista lógico, a sua conclusão de que os gastos de consumo e investimento dos capitalistas determinam lucros brutos implica a formulação do princípio da demanda efetiva. A teoria da demanda efetiva pode ser derivada da equação (1), que representa a troca entre os Departamentos I e II, de um lado, e o Departamento III, de outro, dentro de um contexto geral.

\section{O equívoco de Bacha e a crítica de Almeida: um entendimento nos termos do PDE}

Bacha (1982), com base na equação $\mathrm{L}=C_{c}+\mathrm{I}$, com L (lucro) sendo igual ao $C_{c}$ (consumo dos capitalistas) + I (investimento), não define claramente o sentido da determinação que caracteriza o princípio da demanda efetiva. $\mathrm{O}$ autor parte de duas hipóteses: a primeira é que se produz aquilo que se demanda; e a segunda é 
que todo salário ganho pelos trabalhadores é gasto com consumo. Todavia, apesar de replicar essas condições de Kalecki, Bacha não prova o PDE de Kalecki. Bacha (1982) acaba desviando-se do que deveria demonstrar: o PDE de Kalecki. Supondo que apenas os capitalistas acumulam riqueza, então eles poderiam ter acesso ao crédito para bancar parte dos seus gastos. Nos dizeres de Bacha (1982, p. 28-29):

[...] na hora em que o capitalista determina o seu nível de gastos, ele não está limitado pelo seu nível de renda, ou seja, o capitalista pode gastar, em consumo e em investimento, mais ou menos do que está tirando correntemente como lucro do processo produtivo. [...]. Ou, equivalentemente, ao determinar um nível de investimento, a classe capitalistas não está limitada por sua poupança corrente.

Em outra passagem, Bacha (1982, p. 30) afirma: "O investimento cresceu e o que se ajustou foi a poupança. Este é o princípio da demanda efetiva”. É claro que esse raciocínio de Bacha (1982) não se ajusta ao de Kalecki, pelo menos com a clareza deste. Como lembra Almeida (1982), Bacha toma como hipóteses aquilo que deveria demonstrar por lógica.

$\mathrm{Na}$ verdade, Bacha refugia-se na teoria do crédito para tratar do princípio da demanda efetiva, de forma antecipada. É certo que o crédito disponível de várias fontes de financiamento tem um papel importante de alavancar recursos para financiar gastos de investimentos dos capitalistas para além do autofinanciamento dos gastos dos capitalistas a partir do lucro auferido. Contudo, essa não é a questão que deveria ser tratada. Almeida (1982) chama atenção para essa abordagem de Bacha em dois pontos básicos: o primeiro, crédito e liquidez não devem ser considerados como sinônimos, pois crédito diz respeito ao avanço de poder de compra (dinheiro), e liquidez refere-se ao estado de riqueza (patrimônio) em que se encontram os proprietários de ativos (ativos reais ou financeiros) e à possibilidade de passar, dentro do seu portfólio, de uma posição ilíquida para uma posição líquida ou plenamente líquida; o segundo refere-se à hipótese do crédito restrito apenas aos capitalistas. De fato, apesar de o sistema de crédito ser importante para alavancar mais capitais e lucros, ainda assim, a tomada de crédito implica em endividamento de capitalistas e não capitalistas.

O suposto de que os trabalhadores gastam o que ganham é apenas uma hipótese simplificadora usada por Kalecki para demonstrar o seu PDE, e não o suposto de que os trabalhadores, por não dispor de riqueza, não podem ter acesso a crédito, particularmente ao crédito de consumo, que tem como garantia a renda, e, às 
vezes, nem isso. Até porque os gastos de consumo dos trabalhadores realizam uma parte dos lucros dos capitalistas do Departamento III.

Bacha (1982) se contradiz quando, após descartar a dependência dos gastos de investimentos da poupança, por considerar que os gastos dos capitalistas dependem do crédito, afirma que a elevação dos lucros e, portanto, o aumento da poupança é que financiariam ex post os investimentos. Não se discute que, no capitalismo moderno, os gastos do investimento dependem também do sistema de crédito quando o financiamento dos gastos de investimento ultrapassa o limite do fundo interno da firma. Este é o caso do volume dos gastos de investimento, que podem ser autofinanciados dentro do limite da capacidade de financiamento da firma. Mas, quando os gastos de investimento ultrapassam esse limite do fundo interno, então a firma poderá recorrer ao financiamento externo, mas dentro do princípio do risco crescente.

O PDE de Kalecki não discute a questão do crédito. O problema que realmente interessa é o sentido da determinação causal entre poupança e investimento. E o sentido da determinação causal é: o investimento determina a poupança, e não o contrário. Acrescente-se que o investimento que interessa a Kalecki é o investimento ex ante que ocorre no momento da decisão do empresário-investidor.

Como observa o crítico de Bacha, o economista Júlio Sergio Gomes de Almeida, o investimento deve financiar a si próprio. Mas, nesta situação, Bacha abandonou o PDE para passar a discutir a questão do financiamento do investimento por meio da poupança, uma vez que Kalecki, usando uma lógica simples, negou que a poupança determinasse o investimento. Kalecki demonstrou que é o gasto de investimento que determina a poupança. Nos termos de Kalecki, na verdade, são os gastos em consumo e em investimento da classe capitalista que determinam o lucro total. Logo, o sentido lógico da determinação é dos gastos para a renda, e não o contrário.

\section{Considerações finais}

Na teoria da demanda efetiva de Keynes, a efetivação da compra de bens e serviços pelo consumidor-comprador é a validação da expectativa do empresário da venda dos seus bens e serviços, a partir do momento em que tomou a decisão de produzir, expectativa esta que o induziu a contratar trabalhadores e, portanto, criar empregos no período corrente. 
Keynes (1996) observa que as flutuações do emprego numa economia de mercado têm sido recorrentes e suficientes para impedir que se compreenda a natureza crônica do desemprego involuntário no capitalismo de laissez-faire. De outro modo, a gravidade desse problema social é tamanha que se torna impossível resolvê-la sem lhe compreender a natureza e a relevância do princípio da demanda efetiva.

$\mathrm{O}$ ato de validação das vendas esperadas do produtor-vendedor pelo consumidor-comprador é único, não só porque valida o princípio da demanda efetiva, ao concretizar o ato mercantil-monetário no sentido compra (dinheiro)/venda (mercadoria), mas também porque realiza a demanda efetiva esperada, ex ante, que era apenas uma expectativa que motivou o produtor na tomada de decisão de produzir bens e serviços para um consumidor-comprador virtual do futuro, e efetiva a demanda efetiva, ex post, pelo consumidor-comprador real.

A efetivação do ato de compra (dinheiro) e venda (mercadorias), a partir da decisão autônoma do consumidor-comprador, é importante para o produtor-empresário, porque é o momento em que ele sai do mundo imaginário para entrar no mundo real, independente da surpresa da frustração ou não quanto à igualação ou não entre o valor monetário da venda esperada dos bens e serviços produzidos (ex ante) e o valor monetário das vendas efetivadas dos bens e serviços (ex post) pelo consumidor-comprador real.

Apesar das vantagens da simplicidade e da absoluta dispensa do emprego do termo "equilíbrio" na formulação de Kalecki do seu PDE, ainda assim, a formulação de Kalecki do PDE tem um pequeno inconveniente, que é o de não ter deixado explícita a determinação da produção e do emprego como resultado da decisão autônoma do empresário de produzir mercadorias para consumidores-produtores no futuro, em um ambiente de incerteza, algo diferente do que foi visto, por exemplo, em Keynes. Entretanto, isso em nada afeta a rica teoria macroeconômica de Kalecki e sua formulação lógica do princípio da demanda efetiva por outro caminho. Portanto, fica evidente a importância teórica e, inclusive, histórica do PDE para as ciências econômicas, bem como dos seus principais expoentes, Keynes e Kalecki. São nesses termos que os referidos autores procuraram demonstrar que é a demanda efetiva que determina a oferta, e não o inverso, como nos moldes da Lei de Say. 


\title{
The economic importance of the principle of effective demand in Keynes-Kalecki in the framework of political economy
}

\begin{abstract}
The purpose of this article is to rescue the conceptual proximity relationship between the principle of effective demand by John Maynard Keynes and the principle of effective demand by Michal Kalecki. According to the PDE, economic agents determine the level of output and, therefore, employment when they make the decision to produce or invest in a monetary economy of capitalist production. To criticize Say's Law and, thus, the foundations of economic orthodoxy, Keynes and, later, Kalecki created a legacy through a new taxonomy, which gave political economy a different conceptual framework to criticize say's law and, of course, the fundamentals pertaining to (neo) classical orthodoxy.
\end{abstract}

Keywords: Principle of effective demand. Keynes. Kalecki. Say's Law. Political economy.

\section{La importancia económica del principio de demanda efectiva en Keynes-Kalecki en el marco de la economía política}

\section{Resumen}

El propósito de este artículo es rescatar la relación de proximidad conceptual entre el principio de demanda efectiva de John Maynard Keynes y el principio de demanda efectiva de Michael Kalecki. Según el PDE, los agentes económicos determinan el nivel de producción y, por lo tanto, el empleo cuando toman la decisión de producir o invertir en una economía monetaria de producción capitalista. Para criticar la Ley de Say y, por lo tanto, los fundamentos de la ortodoxia económica, Keynes y, más tarde, Kalecki crearon un legado a través de una nueva taxonomía, que le dio a la economía política un marco conceptual diferente para criticar la Ley de Say y, por supuesto, los fundamentos relacionados con la ortodoxia (neo) clásica.

Palabras clave: Principio de demanda efectiva. Keynes. Kalecki. La ley de Say. Economía política.

Classificação JEL: E00; E12; E60. 


\section{Nota}

1 Na física, a expressão quark significa uma das três partículas hipotéticas que constituiriam a base de todas as partículas atômicas conhecidas.

\section{Referências}

ALMEIDA, Júlio Sérgio de. Bacha e a Demanda Efetiva. Texto Para Discussão № 7, Rio de Janeiro, UFRJ, 1982.

BACHA, Edmar. Introdução à macroeconomia: uma perspectiva brasileira. Rio de Janeiro: Campus, 1982.

CARVALHO, André Cutrim; CARVALHO, David Ferreira. O princípio da demanda efetiva de Keynes como contra-ataque definitivo à Lei de Say dos economistas (neo)clássicos. Economia Ensaios, v. 32, p. 223-247, 2018.

DAVIDSON, Paul. Post Keynesian Macroeconomic Theory: a foundation for Successful economic policies for the twenty-first century. Cambridge: Edward Elgar, 1994.

FEIWEL, George R. Michal Kalecki: Contribuições a la teoria de la política econômica. México: Fondo de Cultura Econômica, 1981.

KALECKI, Michael. O mecanismo da recuperação econômica. In: CRESCIMENTO e Ciclo das Economias Capitalistas. Ensaios selecionados e traduzidos por Jorge Miglioli. São Paulo: Hucitec, 1977.

KALECKI, Michael. A determinação dos lucros e da renda nacional. In: TEORIA da Dinâmica Econômica. São Paulo: Abril Cultural, 1983. (Os Economistas).

KEYNES, John Maynard. A teoria geral do emprego, do juro e da moeda. São Paulo: Nova Cultural, 1996. (Coleção Os Economistas). Disponível em: http://www.ie.ufrj.br/intranet/ie/userintranet/hpp/arquivos/090320170036_Keynes_TeoriaGeraldoempregodojuroedamoeda.pdf. Acesso em: 23 abr. 2020.

MARX, Karl. O Capital (Crítica da Economia política). São Paulo: Civilização Brasileira, 1980.

POSSAS, Mário L.; BALTAR, Paulo. Demanda Efetiva e Dinâmica em Kalecki. Pesquisa e Planejamento, v. 11, n. 1, abr. 1981.

POSSAS, Mário L. Dinâmica da Economia Capitalista: uma abordagem teórica. São Paulo: Brasiliense, 1987.

ROBINSON, Joan. Kalecki e Keynes. In: CONTRIBUIÇÕES à Economia Moderna. Rio de Janeiro: Zahar, 1979.

TORR, Christopher. User cost. In: HARCOURT, G. C.; RIACH, P. A. (ed.). A “second edition” of the general theory. London: Routledge, 1997. v. 1. 